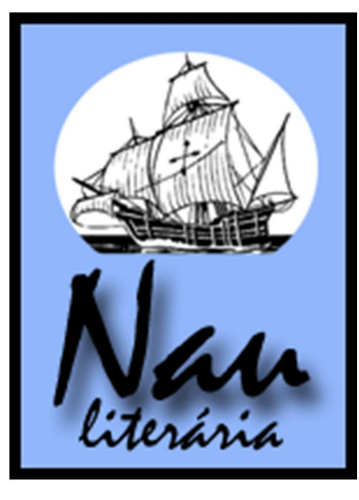

Nau Literária: crítica e teoria de literaturas • seer.ufrgs.br/NauLiteraria

ISSN 1981-4526 • PPG-LET-UFRGS • Porto Alegre • Vol. 07 N. $01 \bullet$ jan/jun 2011

Dossiê: literaturas africanas de LP

\title{
Cronotopias multiculturais e polifonia em As mulheres do meu pai, de José Eduardo Agualusa
}

\author{
José Luís Fornos*
}

Resumo: O presente ensaio visa à análise do romance As mulheres do meu pai (2009), do escritor angolano José Eduardo Agualusa, tendo como reflexão teórica os estudos de M. Bakhtin, Homi Bhabha, Stuart Hall e Boaventura de Sousa Santos. Recorre-se às categorias de raça e de hibridismo, considerando-as numa perspectiva histórica e geográfica. Aponta para a ideia de um cosmopolitismo multicultural como utopia das novas relações internacionais e sociais, através dos princípios de uma hermenêutica diatópica.

Palavras-chave: Espaço Africano; Romance; Multiculturalismo; Deslocamentos.
Abstract: This essay is aimed at analyzing the novel My Father's Wives (2009) by the Angolan writer José Eduardo Agualusa. The study is based on the theoretical bias of M. Bakhtin, Homi Bhabha, Stuart Hall and Boaventura de Sousa Santos. Categories of race and hybridism are approached from a historical and geographical perspective. Analysis results and discussion point to the idea of a multicultural cosmopolitism as the utopia of new international and social relations, through the principles of diatopical hermeneutics.

Keywords: African Space; Novel; Multiculturalism; Displacements.

A multiplicidade cultural gerada pelos deslocamentos, advindos das relações históricas entre impérios, colônias e a globalização, constitui-se num dos temas predominantes nas quinhentas e cinquenta páginas do romance As mulheres do meu pai (2009), do escritor angolano José Eduardo Agualusa. Tal fenômeno, dinamizado por um número elevado de vozes, provoca tensões políticas, étnicas e raciais. $O$ aspecto sexual soma-se a tal configuração, como um poderoso fluxo dos laços geográficos e afetivos, precursor do ambiente multicultural.

As categorias do dialogismo, da polifonia e do cronotopos do encontro e da estrada, são importantes na estruturação de tal romance, construído através da "multiplicidade de vozes e consciências independentes e imiscíveis", constituído de "vozes plenivalentes." (BAKHTIN, 1997, p. 4). Personagens de origens e destinos variáveis que não pertencem ao exclusivo domínio da consciência do autor, participam do diálogo em pé de igualdade, não perdendo autonomia.

\footnotetext{
* Doutor em Teoria da Literatura pela Pontifícia Universidade Católica do Rio Grande do Sul (PUCRS). Professor do Programa de Pós-Graduação em Letras da Universidade Federal do Rio Grande (FURG).
} 
Em termos teóricos, são conceitos que oferecem uma explicação estrutural para a cena plurilíngue da literatura africana. Neste caso, o romance de Agualusa deve ser entendido como uma "diversidade social de linguagens organizadas artisticamente, às vezes de línguas e vozes individuais" (BAKHTIN, 1998, p.74), acrescentando:

A estratificação interna de uma língua nacional única em dialetos sociais, maneirismos de grupos, jargões profissionais, linguagens de gêneros, fala das gerações, das idades, das tendências, das autoridades, dos círculos e das modas passageiras, das linguagens de certos dias e mesmo de certas horas (cada dia tem sua palavra de ordem, seu vocabulário, seus acentos), enfim, toda uma estratificação interna de cada língua em cada momento dado de sua existência histórica constitui premissa indispensável do gênero romanesco. E é graças a esse plurilinguismo social e ao crescimento em seu solo de vozes diferentes que o romance orquestra todos os temas, todo seu mundo objetal, semântico, figurativo e expressivo. (BAKHTIN, 1998, p. 74).

Além dos conceitos de Bakhtin, os princípios de uma hermenêutica diatópica, formulada por Boaventura de Sousa Santos, auxiliam na interpretação do livro. O diálogo intercultural proposto pelo sociólogo português requer a troca de diferentes saberes e culturas, exigindo uma entrega intelectual, moral, afetiva e emocional. Tal entrega só é possível com base numa "identificação profunda com postulados culturais inscritos na personalidade e nas formas básicas de socialização”. (SANTOS, 2003, p. 444). De acordo com Santos:

A hermenêutica diatópica baseia-se na idéia de que os topois de uma dada cultura, por mais fortes que sejam, são incompletos, quanto à própria cultura a que pertencem. Tal incompletude não é visível a partir do interior dessa cultura, uma vez que à aspiração à totalidade induz a que se tome a parte pelo todo. (SANTOS, 2003, p. 444).

Em que pese a importância de tais formulações, é necessário confrontá-las com o espaço diegético. A partir deste, é necessário observar os acréscimos e limites da teoria quando esta se depara com as experiências extraídas das unidades da composição. Sabe-se que o plurilínguismo é uma das marcas do universo literário africano. Todavia, tal multiplicidade de línguas deriva da expressão de povos variáveis que, vivenciando temporalidades distintas, criam microcosmos sócio-culturais cujos sentidos e formas não têm alcance no universo urbano europeu. A interlocução com lugares e formas "originais" traz a participação de novos atores, ampliando o sentido polifônico e dialógico do romance. É o que demonstra, em princípio, o texto de Agualusa.

No romance, duas situações narrativas estruturam o enredo. Uma se pauta pela veracidade, confirmada através de nomes de personalidades vivas como a do próprio autor do livro. A outra é vista exclusivamente como criação ficcional, anunciada como produto da primeira. Ambas resultam de viagens empreendidas por dois grupos. 
Embora estejam separados pelos termos verdade e ficção, os dois relatos não obedecem a tais critérios. A frase "de quantas verdades se faz uma mentira", extraída de um sonho de José Eduardo Agualusa, alerta o leitor das dificuldades em se estabelecer a diferença entre os fatos reais dos inventados. Desta forma, impulsionado pela sentença, Agualusa resolve escrever um roteiro para um filme, abordando a viagem de uma personagem criada por ele, chamada Laurentina, cujo trajeto será similar ao do escritor. Outras similaridades ocorrem, chamando a atenção para a figura do duplo como formato especular da composição textual. Se o motorista do carro do escritor angolano tem por apelido Azarado, no veículo de Laurentina temos o condutor Pouca Sorte. Os sucessos amorosos e a própria redação textual, elaborada em segredo através de um diário, igualmente demarcam as semelhanças das duas figuras principais de viajantes.

Assim, Agualusa e seu motorista, em viagem à África Austral, são acompanhados pelo fotógrafo português Jordi Burch ${ }^{1}$ e a cineasta e musicista Karen Boswall. ${ }^{2}$ Outro dado recorrente e significativo é a condição multicultural das personagens. Todas partilham ou experimentam mais de uma cultura originária. A defesa do caráter multicultural das formações comunitárias parece ser uma das "teses" do romance, pondo em xeque a ideia de tradição enquanto categoria pura e fixa. ${ }^{3}$

Nos capítulos que remetem à viagem ficcional, os destaques são Laurentina, seu namorado Mandume, o escritor angolano Bartolomeu Falcato, seguido do motorista Pouca Sorte. Os lugares visitados se repetem aos do outro grupo. Os objetivos da viagem são, aparentemente, distintos. Os resultados alcançados, todavia, são os mesmos: o reconhecimento das identidades culturais depois de um diagnóstico político da região.

Ao longo da travessia, acontecimentos e situações são relatados por diferentes vozes, criando uma atmosfera ampla e complexa do território africano. Por outro lado, ecoam ainda no imaginário social e individual os sinais das guerras coloniais e civis. Nas capitais em

\footnotetext{
${ }^{1}$ No decorrer do romance, Agualusa faz comentários acerca do fotógrafo Jordi Burch: "Conheci Jordi Burch em outubro de 2004. Fizemos uma reportagem sobre Barcelona para uma revista portuguesa de viagens. Jordi é órfão de pai catalão e mãe portuguesa. Perdeu o pai aos 16 anos e a mãe aos vinte. Perdeu ainda o mais velho dos dois irmãos. Este somatório de tragédias podia ter feito dele um sujeito cínico, inclinado às sombras, propenso á solidão. Pelo contrário, fortaleceu-o. (AGUALUSA, 2009, p. 97-98).

${ }^{2}$ Numa longa entrevista a Agualusa, Karen expõe múltiplos aspectos de sua vida pessoal e profissional. Fala dos pais, comenta a saída de casa em Londres, aos 16 anos, vivendo da música desde cedo em vários países. Começara a tocar flauta aos sete anos. Adiante, revela o período em que se interessou por música africana, passando mais tarde a viver em Moçambique: "Comecei a interessar-me por música africana no início dos anos oitenta. Havia um bar que tocava música africana. Ouvíamos coisas fantásticas. O primeiro músico africano que eu comecei a ouvir foi o Youssou N'Dour. Depois veio o Abdullah Ibrahim, o Hugh Masekela, o Felá Kuti, o Manu Dibango. Cheguei a Moçambique em 1990 para compor música.” (Idem, p. 60).

${ }^{3}$ Homi Bhabha declara que: "A representação da diferença não deve ser lida apressadamente como reflexo de traços culturais ou étnicos preestabelecidos inscritos na lápide fixa da tradição.” (BHABHA, 1998, p. 20).
} 
visita, tradições mesclam-se às novas tecnologias, à miséria, à corrupção e à violência, produzindo um espaço urbano híbrido. Doenças permanecem. As epidemias continuam. Tudo movido e iluminado por uma estrutura polifônica, fortalecida sempre pelas histórias de encontros e contatos.

A presença de tais elementos parece ampliar a perspectiva polifônica e dialógica. A complexidade da consciência plurilíngue é acentuada no universo africano. O acréscimo de línguas e dialetos, ecoando as potencialidades éticas e estéticas das estruturas narrativas africanas, multiplica o poder ideológico do diálogo, demonstrando o quanto ainda falta para uma projeção global das culturas subalternizadas.

A inclusão das inúmeras etnias daquela região projetaria outro internacionalismo, mais polifônico e democrático. Se o contato da rua e a incorporação da palavra do outro possui valor inestimável para o discurso, insere-se neste a força desse multiculturalismo distante dos centros e dos poderes hegemônicos. É através do fluxo das vozes populares, negras, brancas, migrantes, hibridizadas, que se qualificam politicamente as estratégias narrativas, estabelecendo novas confluências textuais e identitárias, fazendo brotar a utopia do cosmopolitismo multicultural.

A cronotopia bakhtiniana do encontro precisa ser relida à luz do que acima se escreveu. Como se sabe, para Bakhtin, "encontro é um dos mais antigos acontecimentos formadores do enredo", devendo-se observar a "estreita ligação do motivo do encontro com motivos da separação, a fuga, o reencontro, a perda, o casamento" (BAKHTIN, 1997, p.224). É preciso dizer igualmente da ligação de tal cronotopo com o da estrada, o que nos leva a refletir sobre a situação do deslocamento e da viagem.

Cabe, então, pensar a questão não abordada por Bakhtin, sobre a caracterização da cronotopia do encontro e da estrada no que se pode designar de produção artística póscolonial. ${ }^{4}$ Atento à caracterização histórico-formal do discurso romanesco, o autor russo enfatiza o romance antigo, no qual o sentido político e geográfico da cronotopia não fora requerido. Segundo Bakhtin, é significativo passar a outro país, mas qual será esse outro país também é absolutamente indiferente. (itálicos meus) As peripécias aventurosas do romance grego "não têm quaisquer ligações substanciais com as particularidades de cada país que

\footnotetext{
${ }^{4}$ Em termos gerais, esse tipo de romance desloca as histórias da modernidade capitalista de seu centro europeu para as periferias dispersas em todo o globo, fazendo multiplicar as conexões, em especial as descentradas e oblíquas, registrando os movimentos migratórios que compõem hoje o mundo. Exalta as questões do hibridismo, da "indecidibilidade cultural" e as complexidades da identificação diaspórica que interrompem a volta a "histórias originais fechadas e centradas em termos étnicos." (HALL, 2003, p. 114).
} 
figura no romance, com sua estrutura sócio-política, sua cultura, sua história.” (BAKHTIN, 1998, p. 224). ${ }^{5}$

Como exemplo crítico da ideia do encontro numa perspectiva pós-colonial, recorre-se a um trecho de Imperialismo e cultura em que Edward Said aborda os contatos entre o colonizador britânico e os nativos na Índia, chamando a atenção de um trecho do romance do escritor inglês E. M. Forster:

A Índia não é uma reunião social, diz Ronny Heaslop. Eu nunca tive notícia de qualquer resultado que não seja catastrófico quando ingleses e os indianos tentam ser íntimos socialmente. Contato, sim. Cortesia, sempre. Intimidade - nunca, nunca. (SAID, 1999, p.257).

Tal caracterização é significativa para verificar como tais encontros e contatos ocorrem numa situação histórica já não mais mediada pelo colonialismo. Produzidos num outro contexto, acabam por promover, além da reflexão do modelo de Estados Nacionais que se projetam no século XXI, ${ }^{6}$ o debate em torno da categoria da hibridação.

As mulheres do meu pai assenta-se nas proposições acima ao reafirmar travessias continentais e nacionais, interferindo no passado/presente das relações entre Portugal, África e Brasil. Somam-se a estes os espaços caribenho e norte-americano. Para tanto, a categoria viagem, favorecedora do intercâmbio e do conhecimento de tradições esquecidas ou desconhecidas, torna-se um imperativo estruturante do texto apontado.

O enredo deriva igualmente da biografia de José Eduardo Agualusa, um escritor viajante que, ao transitar por diversos países, vivencia suas especificidades, acabando por dinamizar os signos da nacionalidade, reencenando zonas de contato ou culturas de fronteiras. De outro modo, esse autor, um habitante do mundo globalizado, que se encontra inconformado com o enraizar-se numa única cultura e nação, engaja-se numa estética diaspórica e multicultural, preocupado em observar e viver as diferenças culturais, incorporando, através de suas personagens, episódios que revelam outros padrões de referência ética e cultural. Tal escritor estrutura seu pensamento de forma dialética ou, como

\footnotetext{
${ }^{5}$ Bakhtin refere-se à épica. No entanto, é possível levar em conta os atributos políticos e sociais numa ótica "orientalista".

${ }^{6}$ Discorrendo sobre o tema, Eric Hobsbawm aponta novos elementos que afetam o nacionalismo do novo século, destacando, entre outros, a extraordinária aceleração do processo de globalização e seu efeito sobre o movimento e a mobilidade dos seres humanos. Escreve o historiador inglês que, ao findar do século, "cerca de 2,6 bilhões de pessoas foram transportadas anualmente pelas linhas áreas de todo o mundo, o que corresponde a uma média de quase uma viagem de avião por ano para cada dois habitantes do planeta." Quanto à globalização das migrações internacionais em massa, Estados Unidos, Canadá e Austrália, "receberam quase 22 milhões de imigrantes provenientes de todas as partes do mundo". Nos anos transcorridos entre 1998 e 2001, esses três países "receberam um influxo de 3,6 milhões de pessoas." A Europa ocidental recebeu quase 11 milhões de estrangeiros durante esse período. Segundo Hobsbawm, o "influxo acelerou-se na entrada do novo milênio", sendo um total de "cerca de 4,5 milhões de pessoas entrou nos quinze países da União Europeia." (HOBSBAWM, 2008, p. 89).
} 
quer Edward Said, de maneira contrapontística. É o que parece ocorrer com Agualusa ao dividir seu tempo entre a Europa, África e Brasil, podendo, com base nestes espaços, experienciar e posicionar-se a favor de uma consciência cosmopolita multicultural.

Nesse sentido, os nacionalismos homogeneizantes são postos em questão. Em entrevista, denuncia o estatuto do nacionalismo como limitação à criação artística e à vida social: "Acredito que o nacionalismo é uma doença que conduz quase sempre a manifestações racistas e xenófobas". O escritor prefere acreditar no "potencial revolucionário da mestiçagem."7 A categoria que une a experiência biográfica e a produção artística é a do hibridismo.

Em As mulheres, a personagem Bartolomeu Falcato defende a mestiçagem cultural como um avanço das relações sociais. Aponta o carnaval como uma das festas essenciais do encontro alegre dos povos, efeito da miscigenação:

O que eu acho é que as sociedades crioulas têm uma vocação natural para a alegria. A mestiçagem produz alegria como um pirilampo produz luz. O carnaval, por exemplo, - Onde é que no mundo se brinca ao carnaval com mais alegria? Isso mesmo: no Brasil, nas Antilhas e em Nova Orleans. Em Goa era na capital, Pangin, no Bairro das Fontainhas, habitado maioritariamente por luso-indianos. Depois os mestiços foram-se e o carnaval morreu. E em África? Resposta: em Luanda, Benguela, Cabo Verde, Cape Town e Quelimane! (AGUALUSA, 2009, p. 209-210). ${ }^{8}$

A inserção de saberes religiosos e mitológicos estranhos ou não à racionalidade europeia também amplia a condição híbrida, ao mesmo tempo em que acentua outro elemento significativo na configuração do texto de Agualusa: o desafio do leitor em decifrar os mosaicos culturais forjados na ancestralidade africana.

Tal alusão faz com que expressões, episódios e relatos mencionados na história mereçam uma investigação à parte como se tratasse de um estudo antropológico. A proliferação metacultural põe em xeque os fundamentos lógicos de uma determinada tradição narrativa, condicionada ao modelo produzido a partir da geografia das metrópoles europeias. É no trânsito e na partilha dos gêneros artísticos que os escritores africanos encenam as identidades hifenizadas, marcadas pela diáspora e pelo hibridismo cultural.

Se o romance As mulheres do meu pai pode ser lido sob a categoria do hibridismo, são relevantes as reflexões de Homi Bhabha a fim de situar a obra. Assim, na emergência dos

\footnotetext{
${ }^{7}$ Entrevista concedida pelo escritor ao jornal gaúcho Zero Hora em vista do lançamento do romance As mulheres do meu pai (2007). ZH, Domingo, 28 de outubro de 2007.

${ }^{8}$ De acordo com Bakhtin, o paradigma carnavalesco oferece princípios significativos para a compreensão do romance e da vida social. Sua originalidade está na flexibilização dos limites estruturais dos textos narrativos e dos sistemas sociais, forjando enquadramentos ideológicos e culturais mais complexos. A "alegre relatividade da cosmovisão carnavalesca" debilita a seriedade retórica unilateral, a racionalidade, a univocidade e o dogmatismo das sociedades.
} 
entre-lugares, ocorrem experiências intersubjetivas e coletivas de nação que, combinadas com o valor da comunidade, precisam ser analisadas.

É a partir da transnacionalidade e da emergência do conceito de tradução cultural, ${ }^{9}$ provocado pelo deslocamento, que devemos compreender tal projeto histórico e literário. Em consequência, Bhabha propõe uma teoria em que despontam sujeitos assinalados pela coabitação assimétrica de culturas num contexto internacional, exigindo uma mudança paradigmática acerca das categorias de nacionalidade, de raça e de classe.

Com efeito, através do ensaio Como o novo entra no mundo; o espaço pós-moderno, os tempos pós-coloniais e as provações da tradução cultural (1998) Bhabha responde a Fredric Jameson, ao chamar a atenção do estudioso norte-americano para a relação capitalcomunidade, problematizando, em contrapartida, a noção de sociedade civil-classe como questionadora do capitalismo. ${ }^{10}$ A comunidade seria a figura que perturbaria a narrativa globalizante do capital, deslocando a ênfase dada à produção na coletividade de classe e rompendo a homogeneidade da comunidade imaginada da nação.

Ao mesmo tempo em que confere poder e valor à comunidade, Bhabha questiona-se acerca das potencialidades discursivas e práticas dessa mesma comunidade, assinalada pelo hibridismo e pela indeterminação: "Pode a perplexidade do mundo estranho, intrapessoal, levar a um tema internacional?" Ou de maneira mais eloquente: "Haverá uma poética da comunidade intersticial?" Ou ainda: "De que forma ela se autonomeia, cria a sua agência?" (BHABHA, 1998, p.317). São perguntas que põem em questão a potencialidade do póscolonialismo enquanto prática política, epistemológica e estética.

As considerações do sociólogo Sérgio Costa (2006) são importantes para se pensar o pós-colonialismo como estratégia política e epistemológica. Costa sustenta que um dos aspectos que põe em risco a teoria pós-colonial como agenciamento da emancipação social

\footnotetext{
${ }^{9}$ Para Bhabha, a ideia de tradução não é a de "transportar fatias suculentas de sentido de um lado da barreira de uma língua para a outra". A cultura como estratégia de sobrevivência é tanto transnacional como tradutória. "A cultura é tradutória porque as histórias espaciais de deslocamento tornam a questão de como a cultura significa, ou o que é significado por cultura." (BHABHA, 1998, p.248).

10 Jameson enfatiza que as categorias de classe "são mais materiais, mais impuras e escandalosamente misturadas no modo pelo qual seus fatores determinantes ou definidores envolvem a produção de objetos e as relações por ela determinadas, assim como a força dos respectivos aparatos: podemos, desse modo, ver, através das categorias de classe, a base de pedra que sustenta o processo." De outro modo, Jameson analisa duas instituições para pôr em xeque o poder expansivo dos grupos de identidade: a mídia e o mercado. Para o autor, a mídia e o mercado proporcionam a "gratificação da identidade psíquica (do nacionalismo à neoetnicidade)". Como destaca o autor: Tendo tais grupos identitários "se tornado imagens, podem se esquecer de seu próprio passado sangrento, da perseguição ao repúdio, e podem agora ser consumidos." (JAMESON, 1996, p.347). Por sua vez, Stuart Hall reconhece que, num mundo controlado pelo capital midiático global, "os espaços conquistados para a diferença são poucos, dispersos e cuidadosamente policiados e regulados" (JAMESON, 1996, p.339). Sabe que tais espaços "são absurdamente sub-financiados", existindo sempre um "preço de cooptação a ser pago", principalmente, quando o "lado cortante da diferença e da transgressão perde o fio na espetacularização.” (HALL, 2003, p. 339).
} 
articulada por Homi Bhabha é que este "evita a remissão à ideia de um sujeito que seja definido pelo vínculo a um lugar na estrutura social ou que seja caracterizado pela defesa de um conjunto de idéias." O sujeito é sempre "um sujeito provisório, circunstancial e cingido entre um sujeito falante e um sujeito falado, reflexivo." (COSTA, 2006, p. 93).

Para a teoria pós-colonial de Bhabha:

A subversão possível é aquela relacionada com o deslizamento do sentido dos signos. A idéia é que os signos possuem possibilidades inesgotáveis de significação e só podem ganhar um sentido particular, ainda assim provisório e incompleto, num contexto significativo determinado. A eficácia da intervenção é também sempre contingente, aberta, indefinida: tratase de uma ação dentro da área de influência do sujeito, mas fora de seu controle. (COSTA, 2006, p. 93-94).

Nesse sentido, Boaventura de Sousa Santos (2003) aposta na equação da teoria crítica com a emergência do pensamento pós-colonial. Defende uma articulação da política com as formulações do multiculturalismo. ${ }^{11}$ Para trazer novamente à cena o internacionalismo libertário é necessária a conjugação de dois paradigmas: o do reconhecimento das identidades culturais e o da superação da desigualdade econômico-social provocada pela dinâmica estrutural do capital. Tal empreendimento denomina de hermenêutica diatópica.

Tal hermenêutica não é executada nem por uma só pessoa, nem a partir de uma única cultura, exigindo um trabalho de cooperação intercultural. Requer um processo diferente de criação de conhecimento em que este seja coletivo, participativo, interativo, intersubjetivo, realizado em redes; "uma produção baseada em trocas cognitivas e afetivas que avançam por intermédio do aprofundamento da reciprocidade entre elas." (SANTOS, 2003, p. 451).

O objetivo dessa hermenêutica não é atingir a completude - um objetivo inatingível mas, ampliar ao máximo a consciência da incompletude mútua por intermédio de um diálogo que se desenrola, por assim dizer, com um pé em uma cultura e outro em outra. O desafio é enorme, sendo muitas as dificuldades para sua concretização.

No romance, as dificuldades de se criar um cosmopolitismo multicultural ocorre desde o momento em que a personagem Laurentina viaja de Portugal para o território africano a fim de conhecer o pai, Faustino Manso, famoso músico angolano que tivera, em princípio, dezoito filhos com distintas mulheres. Uma dessas dificuldades é a de convencer o namorado

\footnotetext{
${ }^{11}$ Boaventura de Sousa Santos adverte para os riscos de se celebrar a condição híbrida diaspórica como situação que "permite uma infinita criatividade", uma vez que a mesma tem sido utilizada "para ocultar as realidades imediatas, econômicas, sociais, políticas e culturais dos imigrantes ou das comunidades diaspóricas." Segundo o autor, "a aura pós-colonial, a celebração da diáspora e o enaltecimento da estética da hibridez tendem a ocultar os conflitos sociais reais em que os grupos imigrantes ou diaspóricos estão envolvidos." (SANTOS, 2006, p. 240).
} 
Mandume, ${ }^{12}$ filho de um casal angolano cujos familiares foram assassinados pelo regime angolano pós-independência.

Embora contrariado, Mandume segue a namorada. Em território africano, Laurentina e Mandume entram em crise, desencadeada, entre outras razões, pelo jovem escritor Bartolomeu Falcato, sobrinho de Laurentina, que põe em xeque a identidade de Mandume, uma vez que este nega suas ligações com a África.

Laurentina, por sua vez, em visita às mulheres, filhos e amigos do pai, vai percebendo a importância de Faustino na constituição de uma rede de relações que ultrapassam a ideia de cultura local. Ao recolher os depoimentos para a elaboração de um documentário acerca do músico, a moça depara-se com um universo complexo e plural em que toda resposta convertese num novo enigma, surpreendendo o leitor a cada passagem. Laurentina compreende a importância da música do pai na criação de um elo identitário maior do que suas raízes nacionais. A origem do violão utilizado por Faustino expressa bem a internacionalização dos ritmos africanos, funcionando como metáfora de um Atlântico negro. ${ }^{13} \mathrm{O}$ instrumento pode ser considerado como um dos fios narrativos, elemento metonímico das trocas culturais, expressas no seu deslocamento dos EUA para a África.

De outro modo, no percurso que se estende de Angola a Moçambique, a rivalidade entre Bartolomeu e Mandume cresce à medida que Laurentina, gradativamente, se aproxima do escritor africano, alimentando o ciúme e a ira do namorado. Mandume expõe os motivos de sua revolta, condenando Angola e a literatura feita num determinado período, numa alusão ao escritor africano que, para romper os grilhões do colonialismo europeu, praticava uma poesia panfletária de combate, enfatizando um nacionalismo de cunho étnico-racial e socialista:

Nunca gostei de África. Vi como a África destruiu os meus pais. Li alguns livros que eles guardam no escritório, isso que alguns chamam de literatura angolana: a vitória é certa camarada! A poesia é uma arma, Sábado vermelho. Panfletos políticos, escritos, o mais das vezes, com os pés. Raízes? Raízes têm as plantas e é por isso que não se podem mover. Eu não tenho raízes. Sou um homem livre. Raízes têm as árvores, nem eu nem tu [Laurentina] somos africanos. (AGUALUSA, 2009, p. 42). ${ }^{14}$

\footnotetext{
${ }^{12}$ Na História de Angola, Mandume fora rei dos Kuanhamas. (AGUALUSA, 1989, p. 169).

${ }^{13}$ São importantes as reflexões e reivindicações teóricas de Paul Gilroy ao defender a tese de um Atlântico negro como unidade de análise única e complexa do mundo moderno para produzir uma perspectiva transnacional e intercultural, em oposição às abordagens nacionalistas ou etnicamente absolutas. A história do Atlântico negro "propicia um meio para reexaminar os problemas de nacionalidade, posicionamento, identidade e memória histórica." (GILROY, 2008, p. 59).

${ }^{14} \mathrm{O}$ deboche e a irritação da personagem podem ser desafiados a partir da seguinte frase: "Ter raízes é talvez a necessidade mais importante e menos reconhecida da alma humana" (SAID, 2003, p. 56) .
} 
Em outra passagem, procura se convencer de que sua identidade é portuguesa: "Felizmente os meus pais ficaram em Portugal. Nasci em Lisboa. Sou português. Houve uma fase da minha vida, entre as dores e os ardores da adolescência, em que tive dúvidas. Não sabia muito bem a que mundo pertencia." (AGUALUSA, 2009, p. 70). Para um conhecido, em contrapartida, a maneira de falar o português e o andar de Mandume eram sinais quase evidentes de sua ligação com a África. Irritado com a insinuação, a personagem afirmava que seus pais haviam nascido em Lisboa.

$\mathrm{O}$ vínculo à pátria paterna e materna é restabelecido quando Mandume descobre a existência de um irmão do pai que, lutando em lado oposto, sobrevivera à guerra civil em Angola. Aos poucos, a personagem aproxima-se do tio, buscando compreender o passado e os hábitos da família do irmão de seu pai. Como Laurentina, Mandume se converte ao tempo e ao espaço africanos.

O romance é um complexo extraordinário de vozes emaranhadas, ganhando coerência artística através de uma orquestração precisa. Como em experiências narrativas anteriores, o escritor articula, com habilidade, a verdade histórica e biográfica com a imaginação literária, posicionando-se em defesa de universos culturais híbridos como emblemas da utopia multicultural.

Nessa direção, não faltam vozes femininas dispostas a subverterem a ordem masculina. Assim, das personagens mulheres, destaco inicialmente Laurentina e Karen Boswall. Esta última, conforme a intriga, Agualusa conhecera em Moçambique. Ao se reencontrarem, no Brasil, num festival dedicado à cinematografia lusófona, os dois planejam "contar a história de uma documentarista portuguesa que viaja até Luanda para assistir ao funeral do pai, Faustino Manso, famoso cantor e compositor angolano.” (AGUALUSA, 2009, p. 17) Além das duas, há ainda a mãe de Laurentina, Alima, de origem muçulmana; Anacleta, a primeira e única mulher de Faustino, segundo convicção da própria; Fatita de Matos, outra eterna apaixonada, mãe de Pitanga de Matos; Juliana e Vitória Manso, as duas últimas com distintas posições acerca do pai; Elisa Mucavale e Seretha Du Toit, uma ex-ministra, e Alfonsina, a menina de rua com a qual Mandume mantêm forte aproximação desde que chegara a Luanda. Cada uma delas possui uma história cujo desfecho remonta o papel da mulher na multiplicação da mestiçagem através de um dos recursos básicos: a sexualidade. Nesse sentido, a esterilidade de Faustino possui uma conotação simbólica exemplar, desestabilizadora do ordenamento romanesco, bem como do lugar do homem na história dos 
povos africanos. ${ }^{15}$ Autorizadas ou não, conscientes ou não, desejadas ou não, submissas ou não, são as mulheres as propagadoras dos amores e da fertilidade multiculturais.

A presença delas amplifica a estrutura multicultural da obra que, por sua vez, qualifica a polifonia bakhtiniana através da descrição de mundos culturais díspares, atualizando o valor da polifonia. Da mitologia à religião, passando por tradições musicais, pelas relações de gênero e pela história política dos povos colonizados e colonizadores, tem-se um África plural, assinalada pelo cruzamento de raças, crenças e etnias. As vozes sociais ecoadas em tais espaços multiplicam as razões multiculturais.

Uma hermenêutica diatópica parece ser a inspiração de As mulheres, em especial quando se conhece o princípio de tal hermenêutica que aponta: "Temos o direito a ser iguais quando a diferença nos inferioriza; temos o direito a ser diferentes quando a igualdade nos descaracteriza." (SANTOS, 2003, p. 458) As tensões e dilemas evocados pelo texto encontram respostas nesta utopia multicultural que é defender a igualdade sempre que a diferença gerar inferioridade, e defender a diferença sempre que a igualdade implicar descaracterização. Para tanto, é preciso criar "estratégias subterrâneas de recodificação e transcodificação" (HALL, 2003, p. 339), propósito operado pelo romance de Agualusa ao apregoar polifonicamente o cosmopolitismo multicultural, interrogando as injustiças globais, nacionais e locais, narrando sobre os motivos de comunidades e indivíduos estarem mergulhados na miséria, na violência e na inferioridade cultural.

É sobre tais questionamentos que o romance As mulheres do meu pai se ampara. É em defesa da mestiçagem como categoria revolucionária que o escritor Bartolomeu Falcato se empenha: "Eu acho que a mestiçagem é por natureza revolucionária. A mestiçagem biológica, cultural, pressupõe inevitavelmente uma ruptura com o sistema, a emergência de algo novo a partir de duas ou mais realidades distintas.” (2009, p. 227) É sob tal constelação conceitual, existencial e histórica que a obra de Agualusa se projeta no conjunto da produção literária de língua portuguesa, dialogando sempre com a história de Angola, cruzando-a com outras regiões e culturas do planeta.

\footnotetext{
${ }^{15}$ A verdadeira condição fisiológica de Faustino contraria o trecho a seguir, impondo certa jocosidade àqueles que essencializam a identidade e o comportamento do homem africano. Bartolomeu Falcato recorda que o avô Faustino Manso teve sete mulheres e dezoito filhos: "Era um homem africano. Aqui em África ainda sabemos fazer filhos, não é como vocês lá na Europa. Quem está a salvar a Europa da implosão demográfica são os imigrantes africanos". (AGUALUSA, 2009, p. 52) Na sequência do diálogo com Laurentina, percebe-se que Bartolomeu diz com ironia e humor as declarações acima.
} 


\section{Referências}

AGUALUSA, José Eduardo. A conjura. Rio de Janeiro: Gryphus, 2009. . As mulheres do meu pai. Rio de Janeiro: Língua Geral, 2009.

BAKHTIN, Mikhail. Questões de estética e de literatura. São Paulo: HUCITEC, 1998. Problemas da poética de Dostoiévski. Rio de Janeiro: Forense Universitária, 1997.

BHABHA, Homi. O local da cultura. Belo Horizonte: Ed. UFMG, 1998.

COSTA, Sérgio. Dois Atlânticos: teoria social, anti-racismo, cosmopolitismo. Belo Horizonte: Ed. UFMG, 2006.

GILROY, Paul. O atlântico negro. Rio de Janeiro: Editora 34, 2008.

HALL, Stuart. Da diáspora: identidades e mediações culturais. Belo Horizonte: Ed. UFMG, 2003.

HOBSBAWN, Eric. Globalização, democracia e terrorismo. São Paulo: Companhia das Letras, 2008.

JAMESON, Fredric. Pós-Modernismo: a lógica cultural do capitalismo tardio. São Paulo: Ática, 1996.

SAID, Edward. Cultura e imperialismo. São Paulo: Companhia das Letras, 1999. Reflexões sobre o exílio e outros ensaios. São Paulo: Companhia das Letras, 2003.

SANTOS, Boaventura de Sousa. A gramática do tempo. São Paulo: Cortez, 2006.

(Org.) Reconhecer para libertar: os caminhos do cosmopolitismo multicultural. Rio de Janeiro: Civilização Brasileira, 2003. 